\title{
GLOBAL TEXT PROJECT: NEW HORIZONS IN TEXT BOOK MARKETING
}

\author{
Leyland F. Pitt, Segal Graduate School of Business, Simon Fraser University, Vancouver, Canada
}

Deon Nel, Department of Marketing, Deakin University, Melbourne, Australia

\author{
Gene van Heerden, Department of Marketing and Communication Management, University of Pretoria, \\ Pretoria, South Africa
}

Anthony Chan, Segal Graduate School of Business, Simon Fraser University, Vancouver, Canada

\begin{abstract}
Purpose - The purpose of this paper is to introduce the global text project (GTP) case. The unique developments of the case provide insight of the many challenges and opportunities created within the open source movement.
\end{abstract}

Design/methodology/approach - A case study was used to illustrate some of the most pertinent and interesting developments in the field of marketing, alluding to the open source environment. A Wikibook was created in collaboration with all the participants of a graduate course and the development of this offering initiated a project called the GTP.

Findings - The open source movement has created new ways of thinking and acting. The contributions, modifications and improvements by all users to the original product provide a platform of continuous improvement and development.

Originality/value - The value of the paper lies in the lessons and challenges learnt from the case especially by those managing the GTP.

Classification of the paper: Case study

Keywords: Publishing; Information operations; Text retrieval; Information media; Globalization; Internet.

\section{Background: open source}

"You can download it from our server, and it's free. The only conditions are that you also help add to, and improve it". These are the words of Rick Watson, an Information Systems professor at the University of Georgia's Terry College of Business. Most university professors can identify with the hours spent searching for the appropriate textbook just to find that nothing is suitable for their course. In 2006, Professor Rick Watson found a solution to this problem. His graduate class produced a textbook that was developed, edited and published by the students in the course for the course.

Universities all over the world use learning management systems (LMS) to support and improve learning. Some of these systems are often more administrative in nature but some learning environments engage the student in the learning process by offering tools such as discussion forums, lesson plans, chat, management of assignments and more. Dalsgaard (2006) is of the opinion that social software should be fully integrated into the LMS in order to support the effectiveness of the learning activities. The project in this paper uses Wiki software to create Wikibooks. The case considers textbook marketing in an educational context and reference is made to the use of Wikis in an educational setting. The case of the global text project (GTP) illustrates the discussions on providing free textbooks. Possible opportunities and challenges are also mentioned. We begin with a short industry background on open source 
development and briefly refers to the use of Wikis in managing knowledge in an educational context. The GTP case is then outlined, and some of the marketing issues are emphasized in the discussion. We conclude by referring to some of the challenges this may hold for a number of stakeholders.

The term OS originated in computer programming. It refers to the source code of a program that is open for viewing and modification where nothing is charged for the downloading and usage of the program (Pitt et al., 2006). This software by definition gives users access to the source code at no cost. As a user you are "free to do with the software as you wish". The source code is also freely distributed (Madey et al., 2002). The license is released to open source software and needs to conform to the open source definition articulated by the open source initiative (http://opencource.org). Many initiatives have attempted to re-establish the endeavor of the free software norm. Some of these initiatives include the berkeley system distribution (BSD), Richard Stallman's free software foundation (FSF) and the creation of the GNU public license. All of these initiatives worked towards an anti-commercial intent of OS, as the concept was not aimed at commercial expansion (Feller and Fitzgerald, 2000). OS offerings in their broadest meaning are "products, services and ideas where the intellectual input of the inventor and producers are nonproprietary in nature" (Pitt et al., 2006).

\section{Collaborative and constructive learning}

Kolb and Fry developed the "Experiential Learning Model" in the early 1970s. This model is composed of four elements: concrete experience, observation of and reflection on that experience, formation of abstract concepts based upon the reflection and testing the new concepts. These four elements are the essence of spiral learning. According to Kolb and Fry (1975) learning can begin with any of the four elements mentioned above but typically starts with concrete experience.

The project in this article takes place in a university setting. Universities are good platforms to explore and initiate OSS developments, because they are regarded as "knowledge-building communities", a term developed by Scardamalia and Bereiter (1994). These communities aim to prepare students to continuously acquire knowledge. Many of these higher educational institutions have been criticized for transmitting fixed bodies of information, which makes the students passive knowledge recipients. Alavi (1994) conducted a review of literature and research on cognitive learning theory and found that no single or unified learning theory exists, however she identified three attributes that assist in creating an environment where effective learning takes place and they are: "active learning and constructing knowledge", "cooperation and teamwork in learning" and "learning via problem solving". The integration of information technology into the learning process has the potential to enhance the effectiveness of learning (Clarke et al., 2001; Hunt et al., 2004), although as some authors (Pitt, 2007) have pointed out, information technology cannot be viewed as a panacea to all educational and pedagogical problems.

The first approach to learning that exemplifies all three the above mentioned attributes is collaborative learning. This concept leads to learning that takes place through interaction but it also focuses on the development of knowledge (Alavi, 1994). The second approach to learning focuses on the development of the individual's own knowledge by actively interacting with their environment. This approach also refers to the construction of knowledge through participation in the process, also referred to as "communal constructivism", (Holmes et al., 2001). The focus of this approach is on building a community of learners where the focus should be the community instead of the individual. Cole (2008) mentions that both the approaches above, constructivist and collaborative create effective learning environments.

\section{Wikis in an educational context}

One of the tools used in this OSS is, a Wiki. In 1995 the Wiki concept was demonstrated by Ward Cunningham. A Wiki is a page or collection of web pages designed to enable anyone who accesses it to contribute or modify content, using a simplified markup language (Oxford English Dictionary). The origins of the word are in dispute - it may be from the Hawaiian word "Wiki", which means fast, while others assert that it is an acronym for "what I know is" (although this may be a "backronym" - an acronym created after the fact) ( The Economist, 2006). As an open technology, Wikis provide a space for 
collaborative process writing. All the various phases in the writing process are recorded and earlier versions can also be provided (Carr et al., 2007). These social software technologies encourage active involvement from all stakeholders to become publishers rather than mere consumers of information.

Wiki technology can be explained in a very simplistic way by referring to it as an editable web site created by the collaborative activities of its visitors. It naturally lends itself to support group processes and knowledge repositories. This technology suits both learning models previously discussed: constructivist and collaborative (Cole, 2008).

Wikis can become an integral part of an open source project. The constructive action of all involved is necessary to create and continuously improve an original offering, while it also needs the collaboration of various stakeholders to distribute, use, complete or form part of the community. In the next section we will outline the case of the GTP.

\section{The global text project}

Rick Watson was looking for a suitable textbook for a graduate course in XML Data Management that he was scheduled to teach. He had taught the class twice before but had not found a suitable text. He spent long hours online searching for an appropriate book to prescribe, as well as perusing the catalogs of all the major academic publishers, but was unable to find anything that met his requirements. By the time the course began, he still hadn't found a text. Almost in desperation, he announced in the first class that the textbook for the course would be written, reviewed, and edited by the course members, and ultimately used by the course members. Students were required to each write a chapter, teach the class the material in the chapter, and develop an exercise to test the key concepts of the chapter. By the end of the course, the class would have an appropriate textbook: one that they had written themselves. A Wikibook was made available after Wiki software was used to write the book. The quality of each chapter and the contributions to improving the chapters of others formed part of the final course grade. The student groups worked long and hard on the chapters and the preparation of their presentations. They also had to endure the criticism of their peers for work that was deemed below standard or incomplete, and witness their efforts being tweaked, edited and improved upon by their fellows. By the end of the course, the class had indeed produced a textbook that met the course's needs quite admirably. The GTP was born.

Watson says: "I hope I haven't made it sound too easy, and I can understand that many people would be concerned about the quality of work students would produce. I would say, remember a few things. First, these were graduate students, with good backgrounds and some knowledge of the course material already. Second, their grades depended to a large extent on what they offered to the course, and their peers were even tougher critics of their work than their instructor. Third, yes there was variability in quality, but we expected that, and the peer-review process helped enormously in leveling that out. And finally of course, the text got better the following year when we used it in the same way again.

The following semester professor Watson had a ready-made text for the course he had to teach, and the next class of students was also encouraged to add to and improve their prescribed text. The students were delighted that their course came with a free textbook. The news of professor Watson's textbook had spread beyond his home institution, and he began to receive inquiries from faculty at other institutions who wanted to teach a similar course. He was asked things like, how could they get the book, and what would it cost? His answer: "You can download it from our server, and it's free. The only conditions are that you also help add to, and improve it". More or less at the same time Don McCubbrey, an Information Systems Clinical Professor in the Daniels College of Business at the University of Denver was teaching an IS class for MBAs without a textbook. Professor McCubbrey prepared a syllabus, and assigned readings that were freely available to students either through articles available in databases subscribed to by the university library or available at no cost on academic and practitioner internet sites. Students appreciated a classroom environment in which current issues were presented using free content. Don had co-authored textbooks too and was well aware of the process followed by most publishers to encourage authors to publish new editions to cut the feet out from under the used book market. He was 
also well aware of the XML text project Rick had underway. They talked at an ICIS Conference, and after a bit of brainstorming, decided to collaborate.

\section{A joint collaborative project}

The developments and discussion made Rick Watson realize that they were on to something far larger than ad hoc textbooks for courses without suitable texts to prescribe. The market was far larger than that for relatively specialized courses, designed for comparatively affluent students at well-established schools in developed nations. If one considered general introductory courses across a wide range of subjects and disciplines, for students in developing countries who would otherwise not be able to afford an education, then the potential market was immense.

\section{The vision of the global text project}

Rick Watson began to develop a vision for the project:

The project will create open content electronic textbooks that will be freely available from a web site. Distribution will also be possible via paper, CD, or DVD. Our goal initially is to focus on content development and Web distribution, and we will work with relevant authorities to facilitate dissemination by other means when bandwidth is unavailable or inadequate. The goal is to make textbooks available to the many who cannot afford them.

Mass education has created tremendous opportunities and wealth for people in developed countries. It has enabled many to escape poverty, albeit a level of poverty that is not comparable to that of many in the developing nations. Mass education for the developing world is dependent among other things on finding low costs means of delivering free quality content to many. We believe we have the means for developing the necessary content and seek support to start an endeavor that can engage many for the benefit of many more. We will work through universities, world development agencies (e.g., World Bank, United Nations), and other appropriate bodies to promote adoption of the texts.

Furthermore, we will work on creating a community that contributes to enhancement of the texts. It is not enough, we believe, to have a simple transfer of knowledge. Rather, we want to engage those who use the books, both instructors and students, to engage actively in improving the quality of the book. For example, cases and exercises based on local events will help to make a text global. Many current texts usually draw heavily on North American situations. Our plan is to work closely with academic opinion leaders in target countries to foster adoption. We think that local champions will be key to spreading adoption (From http://0-globaltext.terry.uga.edu.innopac.up.ac.za/).

As can be seen from this vision the GTP that started off as a graduate course developed into a project that now addressed far greater needs. The two institutions currently working together on this project are the Terry College of Business of the University of Georgia and the Daniels College of Business of the University of Denver. The two leaders, Don McCubbrey and Rick Watson are working together towards the common goal of the GTP.

The project is located and housed in the Terry College of Business, which handles administrative matters. The project has also gained widespread media attention, and has been mentioned and discussed on radio and television, as well as in well known publications such as the Atlanta Journal Constitution, The Chronicle of Higher Education, Christian Science Monitor, Business Week, Der Spiegel, and New Scientist. Don and Rick have also been invited by the Association to Advance Collegiate Schools of Business and the European Foundation for Management Development to give keynote addresses at their major conferences. 


\section{Partnerships}

Early efforts of the GTP engaged a number of alliances in various parts of the world with the aim to increase access to educational material. Some of these working partnerships include: Alternative Media Access Center, committed to providing access to knowledge for individuals with physical, sensory, and learning print-related disabilities; global learning portal (www.glp.net), a network for educators to collaborate with colleagues, access resources, and to browse through education materials, studies and courses and MERLOT Africa Network (http://man.merlot.org/), a networked partnership between African and US educational institutions affiliated with the Multimedia Educational Resource for Learning and Online Teaching (MERLOT) and leading global eLearning providers with development programs targeting Sub-Saharan Africa. Network members work in partnership to develop collaborative projects for development and innovations in the best practices in eLearning solutions. Partners meet twice annually during the MAN Forum, organized as part of eLearning Africa, held in different African countries each year, and the MERLOT Africa Panels, during the annual MERLOT International Conference.

\section{Funding}

An important milestone was achieved in 2007, when the project obtained funding from the Jacobs Foundation, which was established by Klaus J. Jacobs in December, 1988, in Zurich, Switzerland. In 2001, the Jacobs Foundation had a value of 1.5 billion Swiss Francs. The mission of the Jacobs Foundation is to contribute to productive youth development by bringing together basic research, application and intervention projects and through dialogue and network building. It supports research and projects worldwide. The mission of this foundation and the goal of the GTP are aligned which makes this partnership a very valuable one.

\section{Quality assurance}

Quality is one of the major concerns of the GTP. "There is a nagging doubt in many peoples' minds about the quality of the material the GTP will distribute", says Rick Watson. There is a concern that authors might not "freely" give away their best work. The GTP is as concerned about standards as any for-profit publisher. "We don't simply publish anything that's submitted. Whatever is sent to us goes through a review and editing process." In order to address this issue the GTP established a quality assurance board (QAB) that oversees an advises on quality issues (Table I). The members are from major academic institutions from all parts of the world. This QAB oversees the quality of the plans, processes, and products of the GTP.

Two advisors were appointed to the board:

1. Dr Thomas D. Clark, Jr is President of Strategy Associates, LLC and Former Dean of the Ourso College of Business at Louisanna State University.

2. Stephen W. Goodroe is the former Vice President-Global Customer Marketing for The Procter \& Gamble Company. He is an executive-in-residence at the University of Georgia's Terry College of Business.

\begin{tabular}{ll}
\hline Person & Affiliation \\
\hline Raffaella Bianchi & Consultant, Italy \\
Michael Dowling & University of Regensburg, Germany \\
Michael Page & Rotterdam School of Management, Erasmus University, \\
& The Netherlands \\
Ursula Staudinger & Jacob Bremen University, Germany \\
John Taylor “ Ike" Williams & $\begin{array}{l}\text { Fish and Richardson, PC (one of the largest law firms in the } \\
\text { US specializing in intellectual property) }\end{array}$ \\
&
\end{tabular}

Table I.

The GTP quality assurance board

\author{
Consultant, Italy \\ University of Regensburg, Germany \\ Rotterdam School of Management, Erasmus University, \\ Fish and Richardson, PC (one of the largest law firms in the \\ US specializing in intellectual property)
}

Table I The GTP quality assurance board 
The quality assurance board oversees all aspects of the project related to quality. There are four broad phases to quality control:

1. Selection of books to include in the library.

2. Development and enhancement of a book.

3. Development and enhancement of a chapter.

4. Translation of a book.

Phases 2 and 3 (development and enhancement of a book, and development and enhancement of a chapter) are illustrated graphically in Figure 1.

Development and enhancement of a book chapter

Development and enhancement of a book
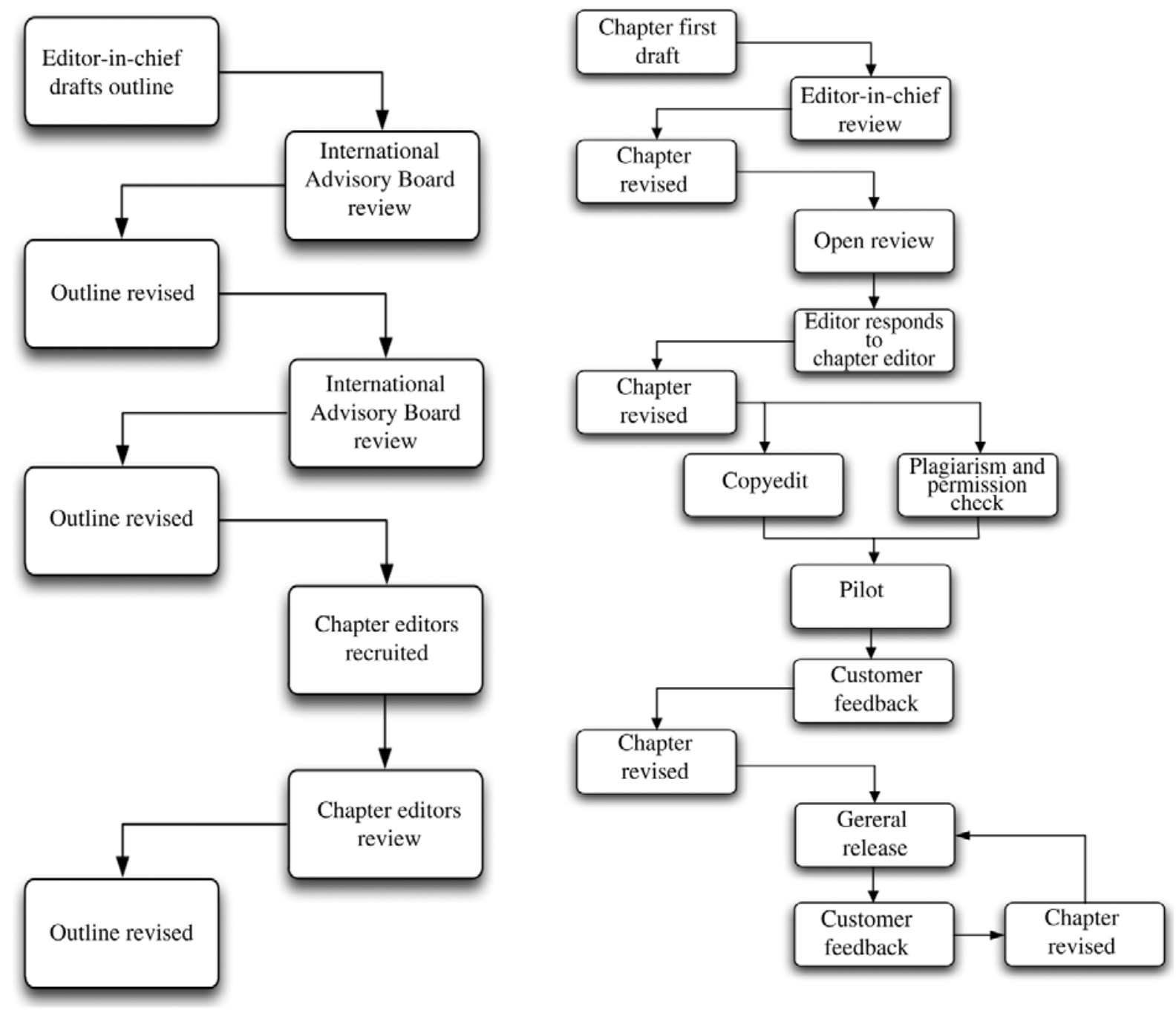

Notes: *The typical timescale of the review and revision procedure is about six months. This can vary depending on the authors and the participants. Evidence suggests that it takes approximately six months Figure 1 Aspects of the quality assurance procedure 
Each textbook should have the necessary degree of consistency and quality to meet educational objectives, therefore an editorial board is created for each book. The goal is to balance the community involvement (i.e. faculty, students, and practitioners) with the need for content, currency and accuracy. Texts are managed as if they were peer-reviewed journals, with an editor-in-chief (EIC) for each book as well as chapter editors. Guidelines for the various roles are made available to prospective contributors.

The GTP also intends to offer scholarships to students who make a valuable contribution to a book. For example, a student who contributes a particularly useful exercise or adds a good Example to a chapter might receive $\$ 100$, which could be a significant reward in many developing countries. Students could also be used to localize a text. For example, a student in Kenya could add an example of a local small business' marketing success. This would give local readers more connection with the text and also readers in other countries would extend their knowledge of regional and cultural differences.

\section{The commercial challenge}

Rick Watson's graduate class produced a free textbook, an OS offering that was published online, where all the various traditional distribution channels were bypassed. The moment Rick Watson received requests from outside his course, the project went outside the "borders and boundaries" of the classroom into the commercial environment.

So what are some of the commercial challenges identified by this project? This project could threaten existing models of textbook publishing, under which for-profit publishing firms commission books from authors, and then produce and distribute them. These firms command good margins on the books they publish, some of which are passed on to the author(s) of a text in the form of royalties. While the nature of royalties usually depend on the contract the author(s) can negotiate with their publisher; typically this is in the range of 15 per cent on gross wholesale sales of a book, and royalty checks are mailed to authors annually or semi-annually. For some academics this means considerable earnings. The author of a successful textbook - for example one selling 20,000 copies a year - could receive an excellent income. If the wholesale price of the book was $\$ 50$ an author might earn around $\$ 150,000$ in royalties in any given year. However, there is a flourishing market in second hand textbooks, so royalties tended to peak in the first year of a text's release, and then decline sharply. In order to overcome this, many authors and publishers regularly update and change texts, so that the second-hand market effect is not too strong.

Rick Watson was himself the author of a number of successful texts in the fields of e-commerce and database management. He was also a series editor on texts in the information systems area for the publisher Wiley. To avoid any conflict of interest, he offered to step down from this role. However, Wiley declined this, and agreed that he could stay on as series editor while heading up the GTP. "They felt they'd rather be closer to the phenomenon than simply ignore it altogether", says Watson. "In fact they have been very supportive and helpful."

From the case it is clear that there is an interconnectivity and collaborative effort between the various stakeholders in this case. A number of stakeholders are identified in this case:

- Community where producing and using the offer is the focus.

- Distributors who distribute and serve these offerings; Users or customers who mainly acquire and use the offering.

- Collaborators who benefit directly through the offerings.

- Competitors who are those of similar nature but are closed source offerings.

Competitors are an interesting case in particular. Essentially, competitors to the GTP are academics who write textbooks and the firms that publish them. "Most authors of a best-selling text are not going to suddenly give it away on Global Text Project", says Watson, "although they might be perplexed that 
others are doing so. However, almost all of the academics I have spoken to would be willing to write a chapter for a co-authored text, or contribute by reviewing a chapter or two". This is very similar to the writing of open-source software, where no programmer writes a whole programmer, but many, widely distributed programmers are willing to contribute small pieces of code that go to make up a whole, and also work at fixing bugs when these arise (Benkler, 2001; 2002).

It is publishers who might be more at risk. "Textbook publishers may be threatened by this model," Watson says. "In many ways they're like the music industry used to be, before the advent of MP3, downloads, and now iTunes. Their business models haven't really changed in many decades."

\section{Initial response}

The initial response to the project was more enthusiastic than Rick Watson had hoped for. He was overwhelmed with communication form all over the world, inquiring about how the "free" books could be obtained. Offers of help and assistance from academics in many countries also came to him. Immediately he started to solicit help and contributions from his wide network of contacts in institutions on all the continents. He found that while few academics were prepared to write and then give away an entire textbook for free, the great majority were quite happy to donate a single chapter, contribute to the review process, or act as editors or associate editors to a co-authored textbook.

All of the books will be released under a Creative Commons Attribution 3.0 License. This license allows for the ready distribution of texts in a variety of formats. The chapters for all books are maintained in open document format with extensive use of style sheets so that they can quickly be converted into different media or formats. Within a short time, the books in exhibit 1 had been produced and were available to adopters. There are also more than 12 books in various stages of preparation and completion.

\section{Future developments}

In the few years since the birth of GTP it has made significant progress, and was beginning to have an impact on the world of education. In early 2008, Rick Watson realized that even though a lot had been achieved there were still many challenges ahead. Among the issues that Watson listed as critical were:

- Workload (the project had developed a life of its own and was already producing as much as a small-to-medium sized publishing firm).

- Incentives and motivation (how could more people - especially students - be encouraged to contribute to the project, and what were the best, and most feasible ways to reward their efforts?).

- Management (was it time to employ someone to manage the project on a daily basis), and related to this.

- Finance (while the Jacobs Foundation had been generous, the project would require more funding as it progressed, and additional sources would need to be identified).

\section{Conclusion}

The initiative started in a graduate course almost due to the sheer desperation of a professor who did not manage to find a suitable text. The project took on a life of its own as it set out its goal of making textbooks available to those who cannot afford them. A Wiki was used to develop the textbook and users were asked to modify and improve on the original product. This initiative poses challenges for the traditional publishing process as the textbooks can be downloaded free of charge. This collaborative tool provides an opportunity for all users and collaborators to contribute to the end product. It is clear that many different stakeholders collaborate in producing or constructing the OS offering. The GTP is managed by two individuals and the project has grown and developed into a more complex system. It is necessary to develop and decide how much structure is needed to effectively manage this project in the future. 
The project discussed in this article specifically addressed the issue of textbook marketing however it provides insight that is almost scalable both horizontally (it covers almost as many disciplines as are taught at universities across the world) and vertically (an individual text that can be used by as many students that need it). This model is not only restricted to textbook marketing in fact it has a lot in common with software marketing because the variable costs involved in publishing conventional textbooks are considerable - printing and distributing a conventional textbook is very costly. Instead, and like software such as Microsoft office 2007, the marginal costs of producing an extra GTP book are close to zero (this of course, assumes that the student simply uses a digital copy of the book; if they print it, they print it themselves or their university does so for them), and then in any case production costs are much lower. In addition, the physical distribution costs are significantly lower than they could ever be for conventional texts.

\section{List of references}

Alavi, M. (1994), "Computer-Mediated Collaborative Learning: An Empirical Evaluation", MIS Quarterly, Vol. 18 No. 2, pp. 159-174.

Benkler, Y. (2001), "The Battle Over the Institutional Ecosystem in the Digital Environment", Communications of the ACM, 44, 2, 84-90.

Benkler, Y. (2002), "Coase's Penguin, or, Linux and the Nature of the Firm", Yale Law Journal, 112, 3, 369-446

Carr, T., Morrison, A., Cox, G., and Deacon, A. (2007), "Weathering wikis: Net-based learning meets political science in a South African University", Computers and Composition, Vol. 24, pp. 266-284.

Cole, M. (2008), "Using Wiki technology to support student engagement: Lessons from the trenches", Computers \& Education, doi:10.1016/j.compedu.2008.07.003

Dalsgaard, C. (2006), "Social software: E-learning beyond learning management systems", European Journal of Open, Distance and E-Learning, Vol. 2, available at http://www.eurodl.org/materials/contrib/2006/Christian_Dalsgaard.htm (accessed 17 November 2008).

Clarke, I., Flaherty, T.B., and Mottner, S (2001), "Student Perceptions of Educational Technology Tools", Journal of Marketing Education, 23, 169-177

Feller, J., and Fitzgerald, B. (2000), "A Framework Analysis of the Open Source Software Development Paradigm", Proceedings of the $21^{\text {st }}$ International Conference on Information Systems 2000, Brisbane pp.10-13.

Hicks, C., and Pachamanova, D. (2007), "Back-propagation of user innovations: The open source compatibility edge", Business Horizons, Vol. 50, pp. 315-324.

Holmes, B., Tangney, B., FitzGibbon, A., Savage,T., and Meehan, S. (2001). "Communal Constructivism: Students constructing learning for as well as with others", Proceedings of SITE 2001, Florida available at www.cs.tcd.ie/publications/tech-reports/reports.01/TCD-CS-2001-04.pdf (accessed 17 November 2008).

Hunt, L., Eagle, L., and Kitchen, P.J. (2004) "Balancing Marketing Education and Information Technology: Matching Needs or Needing a Better Match?, Journal of Marketing Education, 26, 75-88

Kolb. D. A., and Fry, R. (1975) Toward an applied theory of experiential learning. in C. Cooper (ed.) Theories of Group Process, London: John Wiley 
Madey, G., Freeh, V., and Tynan, R. (2002) "The Open Source Software Development Phenomenon: An Analysis Based on Social Network Theory", AMCIS 2002 Proceedings. Paper 247. http://aisel.aisnet.org/amcis2002/247

Pitt, L.F. (2007) "Taking the Tablet: An Introspective Perspective on Using Pen-Based Computing in the Executive Case Class", Journal of Executive Education, 6, 1, 33-40

Pitt, L.F. Watson, R.T. Berthon, P. Wynn, D. and Zinkhan, G. (2006). "The Penguin's Window: Corporate Brands From an Open-Source Perspective", Journal of the Academy of Marketing Science, Vol. 34 No. 2, pp. $115-127$.

Scardamalia, M. and Bereiter, C. (1994), "Computer Support for Knowledge-Building Communities", The Journal of the Learning Sciences, Vol. 3 No. 3, pp265-283.

"The Wiki Principle", (2006), The Economist, 379 8474, April 22 ${ }^{\text {nd }}$, Special Section p14-15 